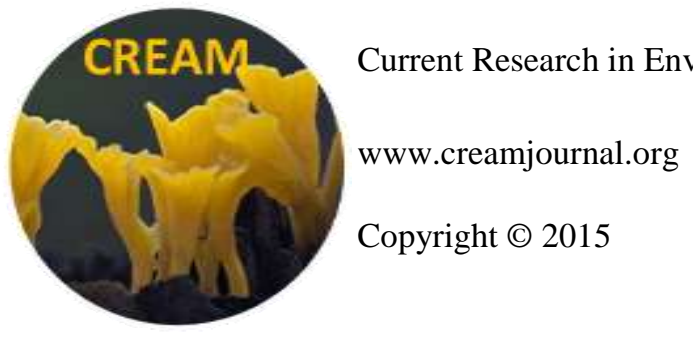

(2): 138-144(2015) ISSN 2229-2225

Article

CREAM

Online Edition

Doi 10.5943/cream/5/2/7

\title{
A new generic record of Boletaceae for Indian mycobiota
}

\section{Chakraborty D and Das K*}

Botanical Survey of India, Cryptogamic Unit, P.O. Botanic Garden, Howrah 711103, India (dyuti.parna.mail@gmail.com, daskanadbsi@gmail.com)

Chakraborty D, Das K 2015 - A new generic record of Boletaceae for Indian mycobiota. Current Research in Environmental \& Applied Mycology 5(2), 138-144, Doi 10.5943/cream/5/2/7

\begin{abstract}
One genus of tubulose fleshy mushrooms belonging to the family Boletaceae, i.e., Rugiboletus is reported for the first time from Sikkim (India) with its macro- and micromorphological descriptions, distribution and supporting illustrations.
\end{abstract}

Key words - Abies - Boletales - macrofungi - Picea - Rugiboletus - Sikkim - taxonomy

\section{Introduction}

Members of Boletaceae are the most dominating fleshy poroid/tubulose ectomycorrhizal mushrooms in subtropical to subalpine Himalaya. Systematic position and circumscription of its members are changing day by day with the aid of molecular phylogenetic analysis. The family is hitherto represented by 64 genera namely, Afroboletus, Alessioporus, Aureoboletus, Australopilus, Austroboletus, Buchwaldoboletus, Butyriboletus, Boletochaete, Boletellus, Boletus, Borangia, Bothia, Caloboletus, Chalciporus, Chamonixia, Corneroboletus, Crocinoboletus, Exsudoporus, Fistulinella, Gastroboletus, Gastroleccinum, Gymnogaster, Harrya, Heliogaster, Hemileccinum, Heimioporus, Imleria, Lanmaoa, Leccinellum, Leccinum, Mucilopilus, Mycoamaranthus, Neoboletus, Notholepiota, Octaviania, Parvixerocomus, Phylloboletellus, Phyllobolites, Phylloporus, Porphyrellus, Pseudoaustroboletus, Pseudoboletus, Pulchroboletus, Pulveroboletus, Retiboletus, Rhodactina, Rossbeevera, Royoungia, Rubinoboletus, Rubroboletus, Rugiboletus, Sinoboletus, Solioccasus, Spongiforma, Strobilomyces, Suillellus, Sutorius, Tubosaeta, Tylopilus, Veloporphyrellus, Xanthoconicum, Xerocomellus, Xerocomus, Zangia (Chiu 1948; Li et al. 2011, 2015; Hosen et al. 2013; Arora \& Frank 2014; Gelardi et al. 2014; Vizzini 2014 a, b, c; Wu et al. 2014, 2015; Zhao et al. 2014; Zhu et al. 2014). Amongst them only 11 genera (Austroboletus, Boletellus, Boletus, Borofutus, Leccinum, Phylloporus, Pulveroboletus, Retiboletus, Strobilomyces, Tylopilus, Xerocomus) are so far reported from India (Singer \& Singh 1971, Ray \& Samajpati 1979, Lakhanpal 1996, Das 2012, Das et al. 2012, 2014, Parihar et al 2014, Das \& Dentinger 2015), one of the 17 megadiverse countries of the world.

During repeated macrofungal surveys to the North and East district of Sikkim (one of the small Himalayan states), we repeatedly came across one interesting member of Boletaceae from Dombang valley, Shingba Rhododendron Wildlife Sanctuary of North district and Memainchu (Maimenchu) of East district in Sikkim. After thorough macro- and micromorphological examination, they appeared as one recently established but hitherto unrecorded genus from India namely, Rugiboletus (Wu et al 2015). 
The genus Rugiboletus G. Wu \& Zhu L. Yang, is featured as: wrinkled/convoluted and glutinous surface of pileus, yellow tubes, dot like squamules or scabers on stipe surface and an ixotrichodermis nature of pileipellis. It is represented by two species, Rugiboletus brunneiporus G.Wu \& Zhu L. Yang and R. extremiorientalis (Lj.N. Vassiljeva) G.Wu \& Zhu L. Yang, (Wu et al. 2015).

Present communication provides a detailed description along with the morphological illustrations of Rugiboletus brunneiporus for the first time from India.

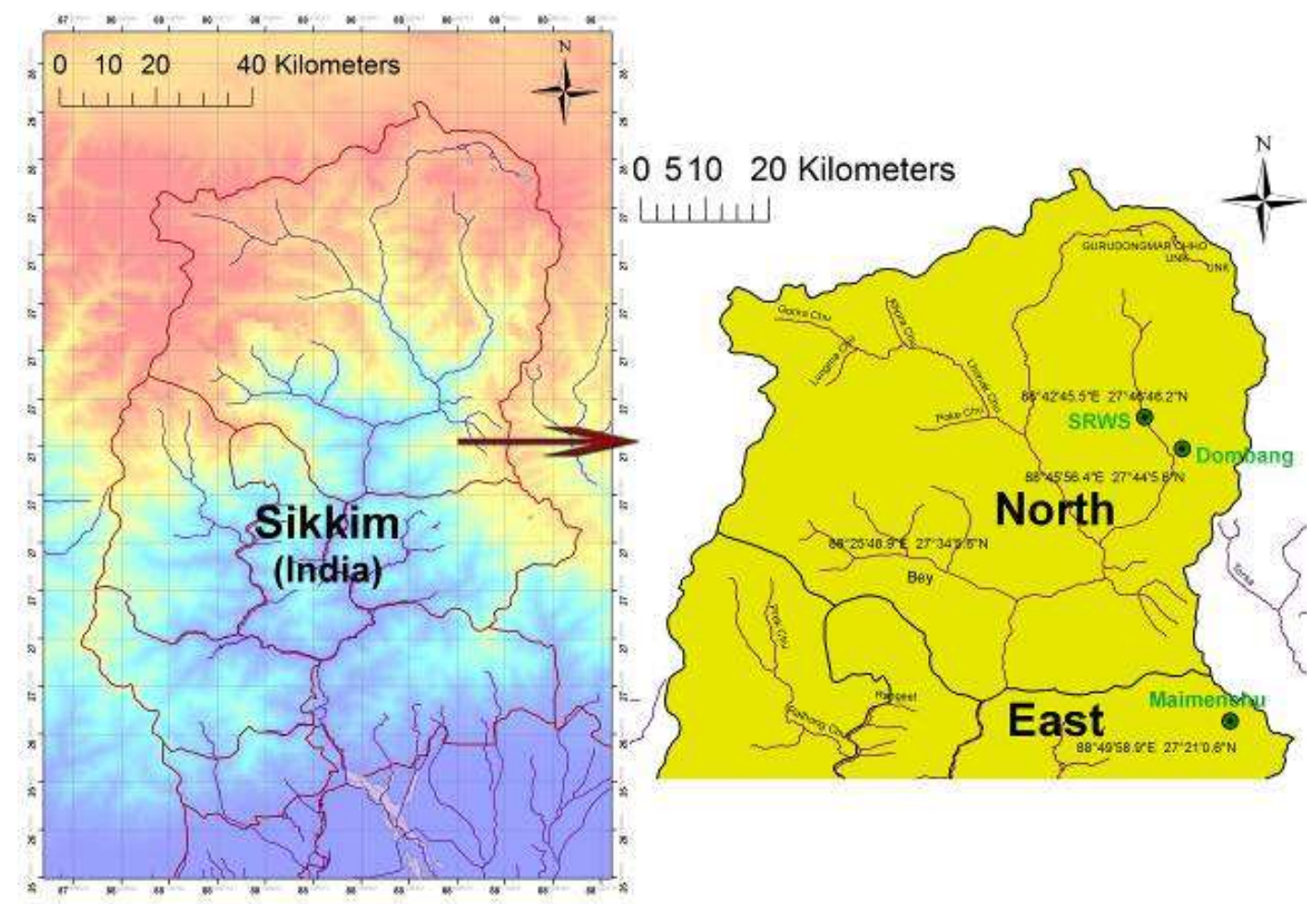

Fig. 1 - A map showing the geographical distribution of Rugiboletus brunneiporus (green spots) in Sikkim (India).

\section{Materials \& Methods}

Routine macrofungal forays were undertaken during the rainy season (July to September) of 2011 to 2014 exploring subtropical to subalpine forests (1400m to 4000m) of North and East district of Sikkim. Macromorphological characterization was made from the fresh basidiomata in the field, including macrochemical (with $\mathrm{KOH}, \mathrm{FeSO}_{4}$ and Guiacol) color-reactions, prior to drying with a portable dryer. Photographs of fresh basidiomata and microphotographs were taken with a Nikon D300s, Olympus C-5060 and Nikon-DS-Ni1 (dedicated to Nikon Eclipse Ni-U compound microscope) cameras. Color codes and terms mostly follow Methuen Handbook of Color (Kornerup \& Wanscher, 1978). Micromorphological characters were recorded with the help of compound microscopes (Olympus CX 41, Nikon Eclipse Ni-U) and a Stereo Zoom Dissecting Microscope (Nikon SMZ 1500) from free hand sections of dry materials mounted in $5 \% \mathrm{KOH}$, or stained in a mixture of $5 \% \mathrm{KOH}$ and phloxin and mounted in $30 \%$ glycerol and Melzer's reagent. Drawings were made with a drawing tube (attached to an Olympus CX41 microscope) at 1000x. Basidium length excludes length of sterigmata. Sporemeasurements were recorded in profile view from twenty basidiospores. Spore-size measurements and length/width ratios $(\mathrm{Q})$ are given as: minimum-mean-maximum. Herbarium code follows Holmgren et al., 1990. Scanning Electron Microscope (SEM) images of basidiospores were obtained from dry spores being directly mounted on a double-sided adhesive tape pasted on a metallic specimen-stub and then were scanned with gold coating of $5 \mathrm{~nm}$ at different magnifications in high vacuum mode $(20 \mathrm{KV})$ to observe patterns of spore-ornamentation. SEM work was carried out with a ZEISS EVO 40EP model imported from Germany and installed at Wadia Institute of Himalayan Geology, Dehradun, India. 
Pileus 60-195 mm. diam.; spherical to hemispherical when young, becoming convex when mature; surface rough to subvelvety, glutinous, wrinkled when young, become distinctly areolate and cracked when mature, in combination of reddish yellow to greyish yellow, brown (4A6, 4B5, 7D8), or darker; margin with sterile flap of tissue, sometimes interrupted with age. Pore surface yellow with reddish brown mouth (8E6), turning blue after bruising; pore 4-7/mm, simple, round. Tube $15 \mathrm{~mm}$ long, adnexed-sinuate, yellow, becoming blue immediately after bruising. Stipe 22.5$140 \times 5-32 \mathrm{~mm}$, central, with reddish brown to greyish brown $(9 \mathrm{~F} 6,8 \mathrm{E} 7,9 \mathrm{~F} 3)$ or darker projected squamules or scabers on maize yellow (4A6) background. Context solid in pileus and stipe; in pileus, initially light yellow (3A5), in combination with ochraceous, deep yellow to orange yellow (4A8-4B8) or brown, turning blue when cut, turning brownish orange to brown(7C8-7D8) with $\mathrm{KOH}$, olive brown (4D4) with $\mathrm{FeSO}_{4}$ and deep yellow (4A8) with guiacol. Spore print olive brown.

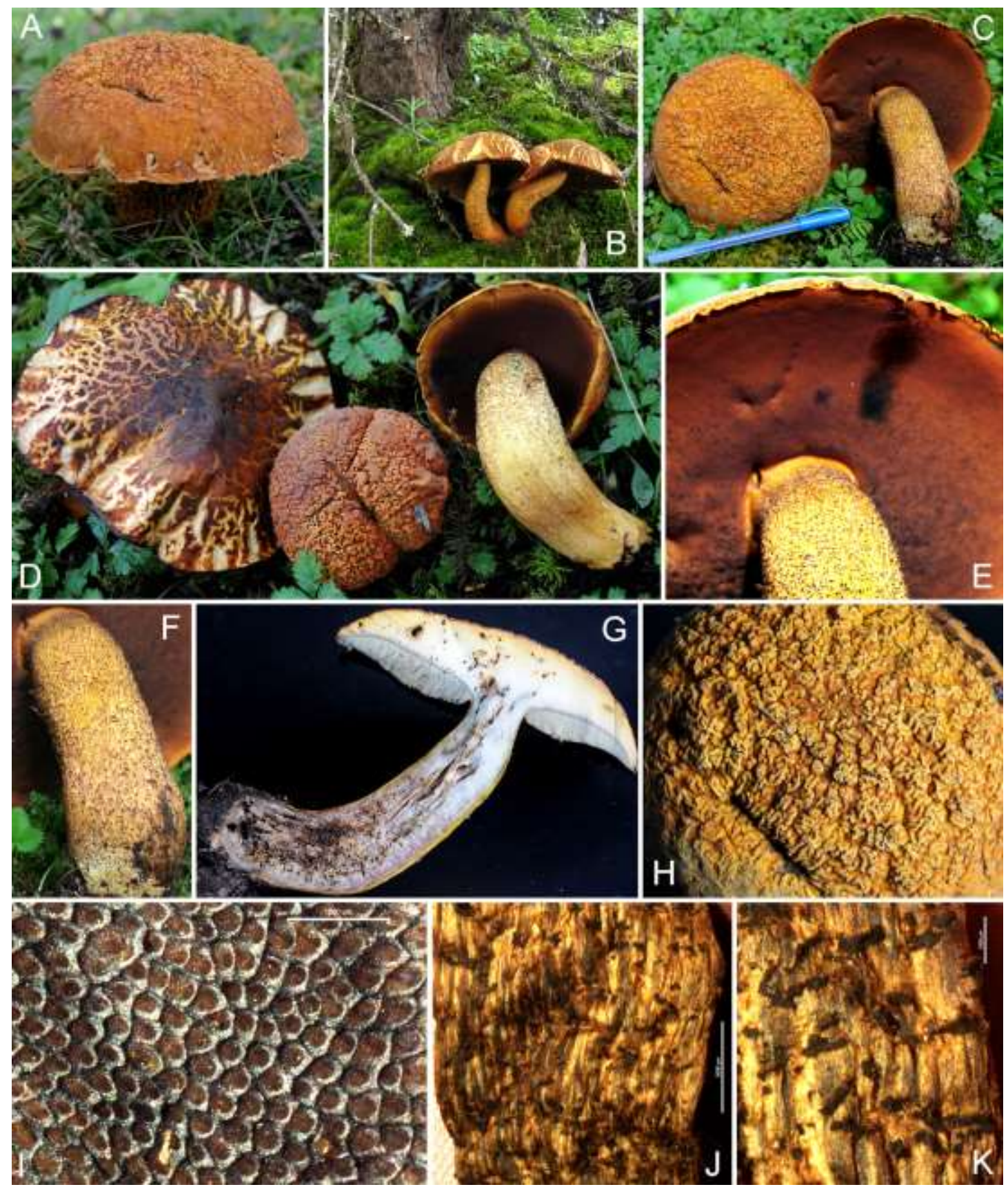

Fig 2 - Rugiboletus brunneiporus. A, B, C, D Fresh basidiomata in field. E Pore surface. F Stipe surface. G Context. H Pileus surface of young basidiomata. I Pore. J, K Dark greyish brown squamules or scabers on stipe surface. - Bars: I, $\mathrm{K}=1000 \mu \mathrm{m} ; \mathrm{J}=5000 \mu \mathrm{m}$. 


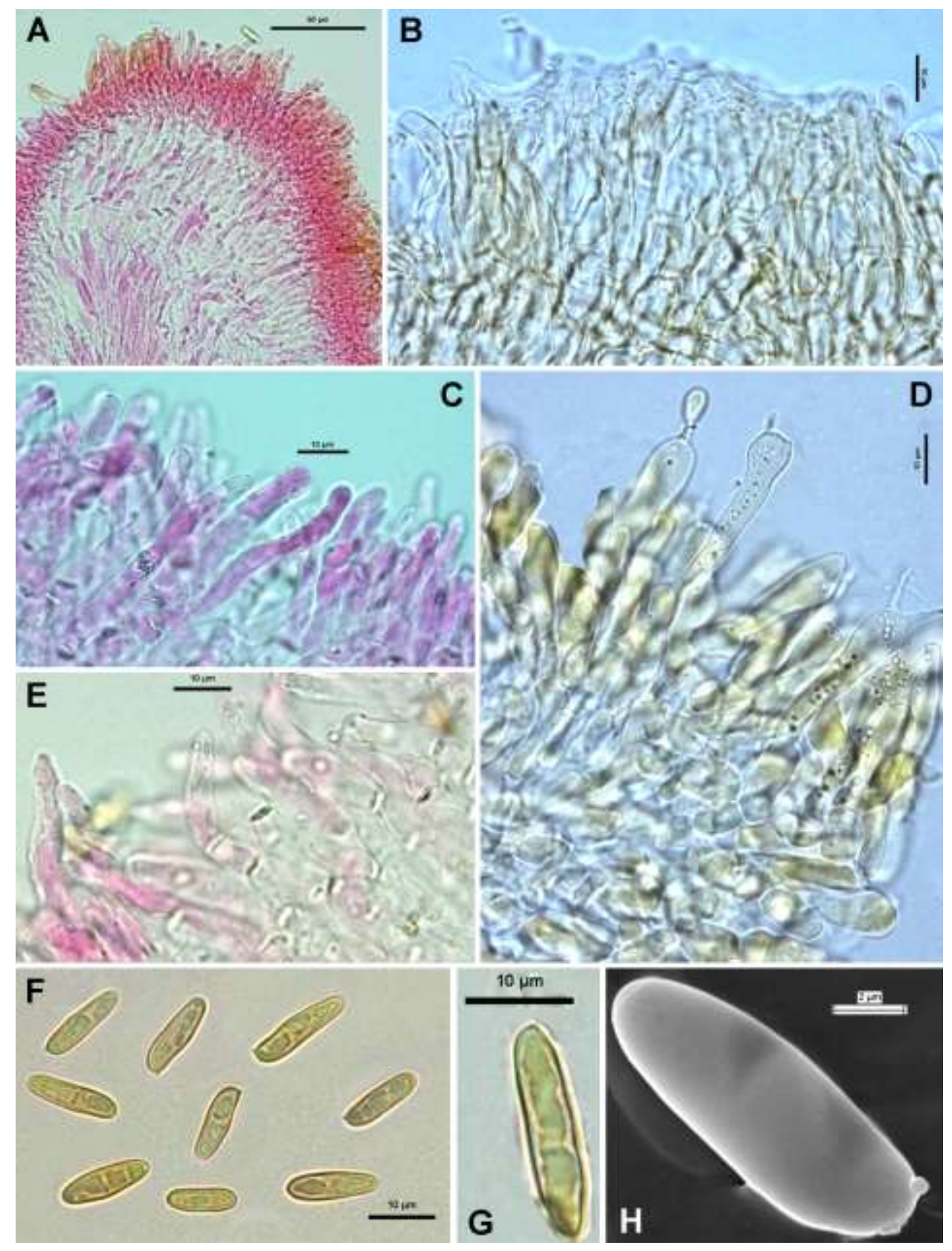

Fig 3 - Rugiboletus brunneiporus. A Tube edge. B Pileipellis showing ixotrichodermis nature. C, E Terminal encrusted cells of pileipellis. D Stipitipellis showing caulocystidia and caulobasidia. F, G Basidiospores. H Scaning electron micrograph of a basidiospore. - Bars: $\mathrm{A}=50 \mu \mathrm{m} ; \mathrm{B}, \mathrm{C}, \mathrm{D}, \mathrm{E}, \mathrm{F}$, $\mathrm{G}=10 \mu \mathrm{m} ; \mathrm{H}=2 \mu \mathrm{m}$.

Basidiospores 10.9-12.8-14.2 × 3.9-3.9-4.3 $\mu \mathrm{m}(\mathrm{n}=20, \mathrm{Q}=2.75-3.21-3.52)$, oblong, inequilateral, smooth under light microscope and under SEM, olivecious brown. Basidia 30-38 $\times 8.5-10.5 \mu \mathrm{m}, 4$ spored, sometime 2 spored, clavate to subclavate; sterigmata up to $4 \mu \mathrm{m}$ high. Pleurocystidia $27-47 \times 5.5-8.5 \mu \mathrm{m}$, emergent $8-18 \mu \mathrm{m}$, less common, subfusiform to ventricoserostrate, content dense granular. Tube edge fertile, composed of basidia and cheilocystidia. Cheilocystidia shorter than pleurocystidia, common, slightly emergent, cylindrical to subventricose to ventricose. Hymenophoral trama divergent. Pileipellis $230 \mu \mathrm{m}$ thick, ixotrichoderm, composed of densely packed, erect, septate, incrusted hyphae (up to $13 \mu \mathrm{m}$ wide); terminal cell cylindrical to fusoid or ventricose with rounded to slightly appendiculate apices. Stipitipellis 100-130 $\mu \mathrm{m}$ thick, fertile, composed of hyphae, basidia and cystidia; caulocystidia 22-40 × 5-9 $\mu \mathrm{m}$, subfusoid to ventricose with rounded to appendiculate apices, content dense; caulobasidia 19-29 $\times 7-9 \mu \mathrm{m}$, slightly narrower than tube basidia. Clamp connections absent. 


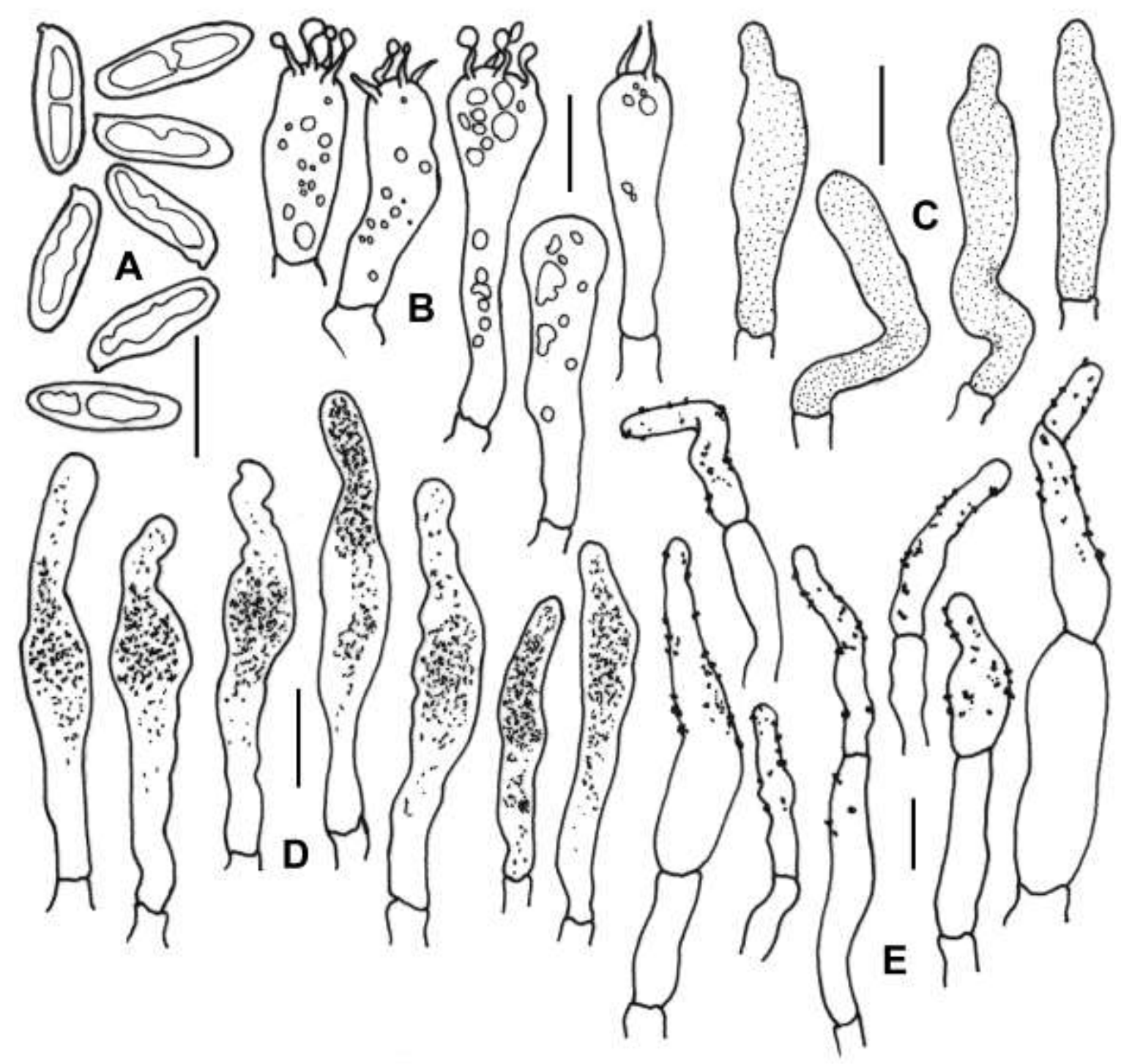

Fig. 4 - Rugiboletus brunneiporus. A Basidiospores. B Tube- and caulobasidia. C Caulocystidia. D. Pleurocystidia. E Terminal encrusted cells of pileipellis. - Bars $=10 \mu \mathrm{m}$.

Distribution - Southwestern China, India (Sikkim).

Materials examined - India, Sikkim, North District, Dombang, 2897 m, N2744'05.6" E88 45'56.4”, under Picea spinulosa (Griff.) A. Henry, 20 August 2011, K. Das, KD 11-033 (CAL); ibid., North District, Shingba Rhododendron Sanctuary, $3556 \mathrm{~m}, \mathrm{~N}^{\circ} 7^{\circ} 46^{\prime} 46.2^{\prime \prime}$ E88 42'45.5”, under Abies densa Griff., 26 July 2011, K. Das, KD 13-050 (CAL); India, Sikkim, East District, Memainchu (Maimenchu), 3601 m, N27²1'0.6” E8849'58.9”, A. densa, 2 August 2014, D. Chakraborty, DC 14-022 (CAL).

Notes - Morphologically, Rugiboletus brunneiporus is very much close to $R$. extremiorientalis and quite confusing in field but the latter one can be separated from the former by its unchanging (on exposure) yellow tube and pore surface (which is reddish brown and bluing immediately in $R$. brunneiporus), smaller (11-13 $\mu \mathrm{m}$ long) spores. Moreover, $R$. extremiorientalis is always found in association with members of Fagaceae (Quercus sp., Castanopsis sp., Lithocarpus sp.) (Wu et al. 2015).

Indian collections are in conformity of all the morphological characters with its Chinese counterpart except the the basidiospores with are longer (up to $21 \mu \mathrm{m}$ ) in the samples collected from Memainchu (Fig. 3 g). 


\section{Acknowledgements}

We are grateful to the Director, Botanical Survey of India, Kolkata and for providing facilities during this study. We thank the entire forest department of Govt. of Sikkim for kindly issueing the permit for macrofungal suvey to the restricted areas of North Sikkim. Thanks are also due to Dr. Md. N. Aziz (BSI, Cryptogamic Unit, Howrah) and Dr. P. Lakshminarasimhan (BSI, Central National Herbarium) for helping us in many ways. Mr. S. Pradhan and Mr. R.K. Ram (BSI, Gangtok) are duly acknowledged for their assistance in the field. Help rendered by Wadia Institute of Himalayan Geology, Dehradun, to obtain the SEM image is duly acknowledged.

\section{References}

Arora D, Frank JL 2014 - Clarifying the butter Boletes: a new genus, Butyriboletus, is established to accommodate Boletus sect. Appendiculati, and six new species are described. Mycologia 106(3), 464-480, DOI: 10.3852/13-052.

Chiu WF 1948 - The boletes of Yunnan. Mycologia 40, 199-231, doi:10.2307/3755085.

Das K 2012 - New distributional record of Retiboletus ornatipes (Peck) Binder \& Bresinsky (Boletaceae) from North and West districts of Sikkim. Indian Journal of Plant Sciences 2(1), $1-5$.

Das K, Dentinger BTM 2015 - Austroboletus olivaceoglutinosus, a new mushroom species from Sikkim, India with a distinctive green, glutinous pileus. Kew Bull. 70, DOI 10.1007/S12225015-9563-Z.

Das K, Hembrom ME, Parihar A, Mishra D, Sharma JR 2014 - Strobilomyces polypyramis rediscovery of a wild mushroom from Sikkim, India. Indian Journal of Plant Sciences 3(2), $13-18$.

Das K, Sharma JR, Mishra D 2012 - Tylopilus pseudoscaber (Secretan) Smith \& Thiers - an addition to Indian mycoflora. Nelumbo 54, 269-272.

Gelardi M, Simonini G, Ercole E, Vizzini A 2014 - Alessioporus and Pulchroboletus gen. nov. (Boletaceae, Boletineae), two novel genera to accommodate Xerocomus ichnusanus and X. roseoalbidus from European Mediterranean basin: molecular and morphological evidence. Mycologia. http://dx.doi.org/10.3852/14-042.

Holmgren PK, Holmgren NH, Barnett LC (editors) 1990 - Index Herbariorum. Part I: The Herbaria of the world [Regnum Veg. vol. 120]. New York: New York Botnacial Garden.

Hosen MI, Feng B, Wu G, Zhu XT, Li YC, Yang ZL 2013 - Borofutus, a new genus of Boletaceae from tropical Asia: phylogeny, morphology and taxonomy. Fungal Diversity 58, 215-226, DOI 10.1007/s13225-012-0211-8.

Kornerup A, Wanscher JH 1978 - Methuen Handbook of Colour. 3rd ed. London, UK, Eyre Methuen Ltd. Reprint.

Lakhanpal TN 1996 - Mushrooms of Indian Boletaceae 1. APH publishing corporation, New Delhi.

Li YC, Feng B, Yang ZL 2011 - Zangia, a new genus of Boletaceae supported by molecular and morphological evidence. Fungal Diversity 49, 125-143, DOI 10.1007/s13225-011-0096-y

Li YC, Feng B, Zeng NK, Cui YY, Yang ZL 2015 - A new genus Pseudoaustroboletus (Boletaceae, Boletales) from Asia as inferred from molecular and morphological data. Mycological Progress 13, 1207-1216.

Parihar A, Hembrom M, Das K 2014 - Borofutus dhakanus (Boletaceae), an addition for Indian mycobiota. Nelumbo 56, (in press).

Ray S, Samajpati N 1979 - Agaricales of West Bengal-iv. Indian J. Mycol. Res. 17, 65-82.

Singer R, Singh B 1971 - Two new ectotroph formig Boletes from India. Mycopath. Myc. Appl. $43,25-33$.

Vizzini A 2014a - Nomenclatural novelties. Index fungorum 146, 1-2.

Vizzini A 2014b - Nomenclatural novelties. Index fungorum 183, 1.

Vizzini A 2014c - Nomenclatural novelties. Index fungorum 192, 1. 
Wu G, Feng B, Xu J, Zhu XT, Li YC, Zeng NK, Hosen IMd, Yang ZL 2014 - Molecular phylogenetic analyses redefine seven major clades and reveal 22 new generic clades in the fungal family Boletaceae. Fungal Diversity DOI 10.1007/s13225-014-0283-8

Wu G, Zhao K, Li YC, Zeng NK, Feng B, Halling RE, Yang ZL 2015 - Four new genera of the fungal family Boletaceae. Fungal Diversity 10.1007/s13225-015-0322-0

Zhao K, Wu G, Yang ZL 2014 - A new genus, Rubroboletus, to accommodate Boletus sinicus and its allies. Phytotaxa 188(2), 61-71, http://dx.doi.org/10.11646/phytotaxa.188.2.1

Zhu XT, Li YC,Wu G, Feng B, Zhao K, Gelardi M, Kost GW, Yang ZL 2014 - The genus Imleria (Boletaceae) in East Asia. Phytotaxa 191 (1), 081-098, http://dx.doi.org/10.11646/phytotaxa.191.1.5 